\title{
As Tecnologias Digitais de Informação e Comunicação para o ensino e a aprendizagem de Ciências da Natureza e Matemática na perspectiva da BNCC
}

\author{
Digital Information and Communication Technologies for teaching and learning Natural Sciences
} and Mathematics from the BNCC perspective

Tecnologías de Información y Comunicación Digitales para la enseñanza y aprendizaje de Ciencias de la Naturaleza y las Matemáticas desde la perspectiva de la BNCC

\section{Resumo}

Esta pesquisa tem por objetivo analisar o papel das Tecnologias Digitais de Informação e Comunicação (TDIC) para o processo de ensino e de aprendizagem de Ciências da Natureza e Matemática e suas Tecnologias, apresentadas na Base Nacional Comum Curricular (BNCC). Para alcançar o objetivo proposto este estudo adota uma abordagem metodológica de caráter qualitativo, do tipo documental, quanto ao seu delineamento, na qual foi realizada uma análise da BNCC - etapa do Ensino Médio. Como resultados, este trabalho traz uma análise e a discussão sobre as competências e habilidades a serem desenvolvidas a partir do uso das tecnologias digitais para as áreas de Ciências da Natureza e Matemática e suas Tecnologias. Verificamos que a área das Ciências da Natureza possui três competências específicas e 26 habilidades, sendo que as TDIC são abordadas em uma competência com 10 habilidades relacionadas, enquanto a área da Matemática possui cinco competências específicas e 43 habilidades das quais quatro competências e 19 habilidades sugerem o uso das TDIC. Com esses resultados pode-se concluir que as TDIC são importantes para o processo de ensino e aprendizagem, pois corroboram para o desenvolvimento das competências e habilidades nas áreas de Ciências da Natureza e Matemática e suas Tecnologias.

Palavras-chave: BNCC; Ensino; Ensino de ciências da natureza; Ensino de matemática; Tecnologias digitais; TDIC.

\begin{abstract}
This research aims to analyze the role of Digital Information and Communication Technologies (DICT) for the teaching and learning process of Natural Sciences and Mathematics and its Technologies, presented at Common National Curricular Base (BNCC). To achieve the proposed objective, this study adopts a qualitative methodological approach, of documentary type, as to its outline, in which an analysis of the BNCC - High School stage was carried out. As a result, this work brings an analysis and discussion about the competences and skills to be developed from the use of digital technologies for the areas of Natural Sciences and Mathematics and their Technologies. We found that the area of Natural Sciences has three specific competences and 26 skills, with DICT being addressed in one competency with 10 related skills, while the Mathematics area has five specific competences and 43 skills of which four competences and 19 skills suggest the use of DICT. With these results, it can be concluded that DICT are important for the teaching and learning process, as they support the development of competences and skills in the areas of Natural Sciences and Mathematics and their Technologies.
\end{abstract}

Keywords: Teaching; Teaching of natural sciences; Mathematics teaching; Digital technologies; DICT.

\section{Resumen}

Incluir o resumo em espanhol. Esta investigación tiene como objetivo analizar el papel de las Tecnologías Digitales de Información y Comunicación (TDIC) para el proceso de enseñanza y aprendizaje de las Ciencias Naturales y 
Matemáticas y sus Tecnologías, presentado en la Base Curricular Común Nacional (BNCC). Para lograr el objetivo propuesto, este estudio adopta un enfoque metodológico cualitativo, de tipo documental, en cuanto a su trazo, en el que se realizó un análisis de la etapa BNCC - Bachillerato. Como resultado, este trabajo trae un análisis y discusión sobre las competencias y habilidades a desarrollar a partir del uso de tecnologías digitales para las áreas de Ciencias Naturales y Matemáticas y sus Tecnologías. Encontramos que el área de Ciencias Naturales tiene tres competencias específicas y 26 habilidades, siendo TDIC abordado en una competencia con 10 habilidades relacionadas, mientras que el área de Matemáticas tiene cinco competencias específicas y 43 habilidades de las cuales cuatro competencias y 19 habilidades sugieren el uso de TDIC. Con estos resultados se puede concluir que los TDIC son importantes para el proceso de enseñanza y aprendizaje, ya que apoyan el desarrollo de competencias y habilidades en las áreas de Ciencias Naturales y Matemáticas y sus Tecnologías.

Palabras clave: BNCC; Enseñanza; Enseñanza de las ciencias naturales; Enseñanza de las matemáticas; Tecnologías digitales; TDIC.

\section{Introdução}

A Base Nacional Comum Curricular (BNCC) é o documento que propõe diretrizes para o ensino nas escolas durante a Educação Básica. Este é um documento de caráter normativo exclusivo à educação escolar que "define o conjunto orgânico e progressivo de aprendizagens essenciais que todos os alunos devem desenvolver ao longo das etapas e modalidades da Educação Básica”, dentre os aspectos importantes apontados na BNCC estão as tecnologias. (Brasil, 2018, p. 7)

As tecnologias têm um papel importante na BNCC, de tal maneira que neste documento suas competências gerais para a Educação Básica abordam o tema no processo de ensino e aprendizagem.

A Educação Básica é estruturada em três etapas, que são a Educação Infantil, o Ensino Fundamental e o Ensino Médio. A etapa do Ensino Médio tem por objetivo consolidar e aprofundar os conhecimentos alcançados nas etapas anteriores da Educação Básica, a preparação para o mercado de trabalho e para a vida, o aprimoramento do estudante como pessoa humana e a compreensão dos fundamentos científico-tecnológicos dos processos produtivos. (Brasil, 1996). Entretanto, Brasil (2018) destaca diante da preocupação com relação aos índices de aprendizagem, repetência e abandono nesta etapa.

Nesse contexto, o presente trabalho tem por objetivo analisar o papel das Tecnologias Digitais de Informação e Comunicação (TDIC) para o processo de ensino e de aprendizagem de Ciências da Natureza e Matemática e suas Tecnologias apresentadas na BNCC.

Para atingir o objetivo proposto este estudo apresenta uma fundamentação teórica sobre a BNCC e as TDIC, onde serão abordadas as competências e habilidades estabelecidas nesse documento para as áreas de conhecimento de Ciências da Natureza e Matemática e suas Tecnologias para o Ensino Médio. Posteriormente, trazemos a metodologia empregada neste estudo e a análise e discussão dos resultados onde é discutido o papel das TDIC para o desenvolvimento das competências e habilidades estabelecidos na BNCC.

\section{Base Nacional Comum Curricular (BNCC)}

Conforme estabelecido pela LDB (Lei no 9.394/1996) a BNCC é o documento que deve orientar os currículos das redes de ensino das Unidades Federativas, das escolas públicas e privadas das etapas de ensino, a Educação Infantil, o Ensino Fundamental e o Ensino Médio. A BNCC é um documento completo e contemporâneo, este documento teve sua versão final homologada no ano de 2018, com a inclusão da etapa do Ensino Médio. (Brasil, 2018).

Conforme Brasil (2018) na BNCC são estabelecidos os conhecimentos, as competências e as habilidades a serem desenvolvidas pelos estudantes no decorrer de toda a Educação Básica. A Base está estruturada, para cada etapa de escolaridade da Educação Básica, em torno de competências a serem desenvolvidas como expressão dos direitos de aprendizagem e desenvolvimento dos estudantes (Brasil, 2018). 
Competência é definida na BNCC como a "mobilização de conhecimentos, habilidades, atitudes e valores para resolver demandas complexas da vida cotidiana, do pleno exercício da cidadania e do mundo do trabalho.". Se relaciona ao que os estudantes devem "saber" (competências) e o que devem "saber fazer" (habilidades) para garantir as aprendizagens essenciais definidas pelo documento. (Brasil, 2018, p. 8).

No decorrer da Educação Básica, da Educação Infantil até o Ensino Médio, os estudantes devem desenvolver as dez competências gerais para que adquiram em seu processo de aprendizagem e desenvolvimento uma "formação humana integral que vise à construção de uma sociedade justa, democrática e inclusiva.” (Brasil, 2018, p. 25).

No Ensino Médio, de acordo com Brasil (2018) a BNCC está estruturada em quatro áreas do conhecimento conforme estabelecido pela LDB. Estas áreas de conhecimento determinam competências específicas para cada área, essas competências evidenciam como as competências gerais da Educação Básica são apresentadas nas áreas. E para o desenvolvimento das competências específicas de área, na BNCC é apresentado um conjunto de habilidades destacando as aprendizagens fundamentais a serem desenvolvidas pelos estudantes.

As estruturas em relação às áreas de conhecimento de Ciências da Natureza e Matemática e suas Tecnologias são apresentadas neste documento pela definição das competências específicas e habilidades que são correspondentes a cada área. (Brasil, 2018).

\section{As Tecnologias Digitais de Informação e Comunicação}

De acordo com os Parâmetros Curriculares Nacionais (PCN), as Tecnologias de Informação e Comunicação (TIC) englobam "[...] os diferentes meios de comunicação (jornalismo impresso, rádio e televisão), os livros, computadores, etc." (Brasil, 1998, p. 135). Com o advento da tecnologia digital, esses meios de comunicação permitiram o compartilhamento de dados de forma imediata e a interação interpessoal em qualquer tempo e lugar. O termo "Tecnologias Digitais de Informação e Comunicação (TDIC)" é utilizado neste trabalho com referência aos recursos tecnológicos digitais que possibilitam o trânsito de informações tanto físicos (computadores, celulares, tablets etc.) como virtuais (internet, redes sociais e nuvens de dados, sistemas multimídias, gravação de áudio e vídeo, entre outros).

Conforme Costa et al. (2015), o termo Tecnologias de Informação e Comunicação (TIC) é o mais utilizado referindose a dispositivos eletrônicos e tecnológicos como computadores e smartphones, por exemplo, assim como a internet. Tendo em vista o termo TIC ser bastante abrangente, incluindo tecnologias mais antigas, como jornais impressos, por exemplo, autores têm utilizado o termo Tecnologias Digitais de Informação e Comunicação (TDIC) por ser mais específico referindo-se a tecnologias digitais como computadores, smartphones e outros dispositivos capazes de permitir a utilização da internet (Baranauskas, \& Valente, 2013; Costa et al., 2015).

As TDIC estão presentes em nosso cotidiano, segundo Jordão (2019) e tal presença pode ser evidenciada seja no contexto social, econômico, político, educacional e cultural. De acordo com a BNCC "A contemporaneidade é fortemente marcada pelo desenvolvimento tecnológico" (p. 473). As tecnologias digitais têm tido uma presença e influência crescente em nosso cotidiano. Tal impacto também pode ser percebido no ambiente escolar e tende a tornar-se cada vez mais significativo (Brasil, 2018).

Almeida e Valente (2011, p.23) reconhecem que:

as TDIC exigem novas habilidades, e, portanto, a necessidade de trabalhar os diferentes letramentos, cria novos desafios educacionais no sentido de que alunos, educadores e as pessoas em geral devem ter uma maior familiaridade com os novos recursos digitais. [...]. Isso significa que o processo ensino-aprendizagem deve incorporar cada vez mais o uso das TDIC para que os alunos e os educadores possam manipular e aprender a ler, escrever e comunicar-se usando essas modalidades e meios de expressão. 
Conforme Almeida e Silva (2011) as TDIC colaboram significativamente no ambiente escolar pois são ferramentas que contribuem para o processo de ensino e aprendizagem e possibilitam o favorecimento da construção cooperativa e colaborativa, o que possibilita a produção do conhecimento pelo estudante.

As tecnologias têm impactos em nossa sociedade, em nossas relações sociais e no mundo do trabalho, por isso tornase importante a formação das futuras gerações. Nesse sentido, a BNCC, com estas preocupações, apresenta nas competências gerais para a Educação Básica e as diferentes dimensões que caracterizam as tecnologias digitais (TD) em relação a atitudes e valores que são:

- pensamento computacional: envolve as capacidades de compreender, analisar, definir, modelar, resolver, comparar e automatizar problemas e suas soluções, de forma metódica e sistemática, por meio do desenvolvimento de algoritmos;

- mundo digital: envolve as aprendizagens relativas às formas de processar, transmitir e distribuir a informação de maneira segura e confiável em diferentes artefatos digitais - tanto físicos (computadores, celulares, tablets etc.) como virtuais (internet, redes sociais e nuvens de dados, entre outros) -, compreendendo a importância contemporânea de codificar, armazenar e proteger a informação;

- cultura digital: envolve aprendizagens voltadas a uma participação mais consciente e democrática por meio das tecnologias digitais, o que supõe a compreensão dos impactos da revolução digital e dos avanços do mundo digital na sociedade contemporânea, a construção de uma atitude crítica, ética e responsável em relação à multiplicidade de ofertas midiáticas e digitais, aos usos possíveis das diferentes tecnologias e aos conteúdos por elas veiculados, e, também, à fluência no uso da tecnologia digital para expressão de soluções e manifestações culturais de forma contextualizada e crítica. (Brasil, p. 474)

Essas dimensões apresentadas são contempladas no documento para o Ensino Médio de forma a serem aprofundadas as aprendizagens dos anos anteriores objetivando que os estudantes reconheçam as potencialidades das tecnologias digitais de contribuírem em diversas atividades, dentro das áreas de conhecimento, para as práticas sociais e para o mercado de trabalho (Brasil, 2018).

De acordo com Valente (2015) as TDIC permitem uma ampla possibilidade de ações pedagógicas oportunizando diversas atividades que podem ser realizadas por professores e alunos. As TDIC "criam possibilidades de expressão e comunicação, novos letramentos, como a criação e o uso de imagens, sons e animações, e a combinação dessas modalidades, por exemplo." (p.32). Desta maneira é essencial pensarmos de que forma as tecnologias digitais são abordadas nos documentos curriculares, de modo geral, e em como as TDIC podem contribuir para o ensino-aprendizagem dos conceitos, assim como, no desenvolvimento das competências e habilidades.

\section{Metodologia}

Este estudo de caráter qualitativo realiza a análise da Base Nacional Comum Curricular do Ensino Médio. De acordo com Pereira et al. (2018) os métodos qualitativos "são aqueles nos quais é importante a interpretação por parte do pesquisador com suas opiniões sobre o fenômeno em estudo". Corroborando, Marconi e Lakatos (2011, p. 269) destacam que a pesquisa qualitativa possibilita uma "análise mais detalhada sobre as investigações, hábitos, atitudes, tendências de comportamento etc".

Quanto ao seu delineamento, este estudo refere-se a uma pesquisa documental que, conforme Gil (2008, p. 51), "valese de materiais que não receberam ainda um tratamento analítico, ou que ainda não podem ser reelaborados de acordo com os objetivos da pesquisa". Segundo o autor são exemplos de tais materiais os "documentos oficiais, reportagens de jornais, cartas, contratos, diários, filmes, fotografias, gravações etc" (Gil, 2008, p. 51).

Para alcançar o objetivo proposto foi realizado uma busca, junto às competências e habilidades estabelecidas na BNCC para as áreas de Ciências da Natureza e Matemática e suas tecnologias, com os termos: TDIC, tecnologias digitais ou, ainda, a termos que pudessem remeter a alguma(s) TDIC em específico como as palavras "algoritmo(s), comunicação, 
tecnologias, tecnológicos, computacionais, softwares, aplicativos, mídias".

Foi definido como critério de exclusão que as competências onde os termos tecnologias e tecnológicos não abrange o sentido de TDIC não seriam abordados em nossa análise, exceto se em alguma habilidade relacionada a esta competência se faça menção a alguma palavra ou expressão que se refira a alguma TDIC.

\section{Competências Gerais da BNCC Acerca das TDIC}

A BNCC orienta os rumos da Educação Básica no País. É este documento que as escolas, tanto públicas quanto privadas, têm como referência comum e obrigatória para a elaboração dos currículos e propostas pedagógicas, com intuito de promover uma boa qualidade de ensino para os estudantes.

Ao longo da Educação Básica os estudantes devem desenvolver dez competências gerais que são essenciais. Dentre essas, duas destacam a importância da utilização das TDIC, sendo elas as competências gerais 4 e 5 .

A competência 4 destaca que

Utilizar diferentes linguagens - verbal (oral ou visual-motora, como Libras, e escrita), corporal, visual, sonora e digital -, bem como conhecimentos das linguagens artística, matemática e científica, para se expressar e partilhar informações, experiências, ideias e sentimentos em diferentes contextos e produzir sentidos que levem ao entendimento mútuo. (p. 9)

Esta competência baseia-se no desenvolvimento da capacidade de utilização de diferentes linguagens. Dentre essas, a digital é apresentada como uma das linguagens a serem desenvolvidas visando possibilitar a expressão e o compartilhamento de informações, ideias e sentimentos em diferentes contextos.

Quanto à competência 5, esta tem por objetivo

Compreender, utilizar e criar tecnologias digitais de informação e comunicação de forma crítica, significativa, reflexiva e ética nas diversas práticas sociais (incluindo as escolares) para se comunicar, acessar e disseminar informações, produzir conhecimentos, resolver problemas e exercer protagonismo e autoria na vida pessoal e coletiva (p.9).

A competência 5 traz as TDIC como seu foco principal. Nesta competência se tem por objetivo que o estudante compreenda, utilize e crie TDIC adquirindo, desta forma, a capacidade de utilizar as diferentes potencialidades das tecnologias de forma crítica, significativa e ética para comunicação, acesso e produção de informações e conhecimentos e resolução de problemas, exercendo, desta forma, através de tais ações um papel ativo e responsável junto à sociedade.

A BNCC, conforme estabelecida pela LDB no artigo 35-A, para o Ensino Médio, é organizada em quatro áreas de conhecimento, que são: Linguagens e suas Tecnologias, Matemática e suas Tecnologias, Ciências da Natureza e suas Tecnologias e Ciências Humanas e Sociais Aplicadas.

As áreas que aqui iremos abordar serão as de Ciências da Natureza e suas Tecnologias e Matemática e suas Tecnologias. Para cada uma das áreas, a BNCC estabelece competências específicas que devem ser desenvolvidas ao longo das diferentes etapas do ensino básico.

De acordo com Brasil (2018), para o desenvolvimento das competências específicas de cada área é estabelecido um conjunto de habilidades que correspondem a importantes aprendizagens a serem desenvolvidas pelos estudantes no Ensino Médio. As competências e habilidades para o Ensino Médio conforme Brasil (2018) têm por objetivo

consolidar, aprofundar e ampliar a formação integral, atende às finalidades dessa etapa e contribui para que os estudantes possam construir e realizar seu projeto de vida, em consonância com os princípios da justiça, da ética e da cidadania. (p. 471) 
Para a área de conhecimento de Ciências da Natureza e suas Tecnologias no Ensino Médio é oportunizado "aos estudantes ampliar sua compreensão sobre a vida, o nosso planeta e o universo, bem como sua capacidade de refletir, argumentar, propor soluções e enfrentar desafios pessoais e coletivos, locais e globais". (Brasil, 2018, p. 472).

$\mathrm{Na}$ área de conhecimento de Matemática e suas Tecnologias no Ensino Médio os estudantes devem "construir uma visão mais integrada da Matemática, da Matemática com outras áreas do conhecimento e da aplicação da Matemática à realidade." (Brasil, 2018, p. 471)

A BNCC apresenta competências gerais, competências específicas e um conjunto de habilidades para o Ensino Médio que contribuem para o desenvolvimento das competências gerais na escolaridade básica.

\section{As TDIC nas Competências Específicas para o Ensino de Ciências da Natureza e Matemática}

Conforme a BNCC, a área da Ciências da Natureza possui três competências específicas e 26 habilidades, enquanto a área da Matemática possui cinco competências específicas e 43 habilidades a serem desenvolvidas durante o Ensino Médio. As TDIC são abordadas em diferentes competências específicas e habilidades nessas áreas do conhecimento. As competências e habilidades que tratam dessa temática serão discutidas a seguir.

A Figura 1 descreve as designações das competências e das habilidades conforme nomenclatura e códigos alfanuméricos estabelecidos na BNCC.

Figura 1. Códigos alfanuméricos na BNCC.

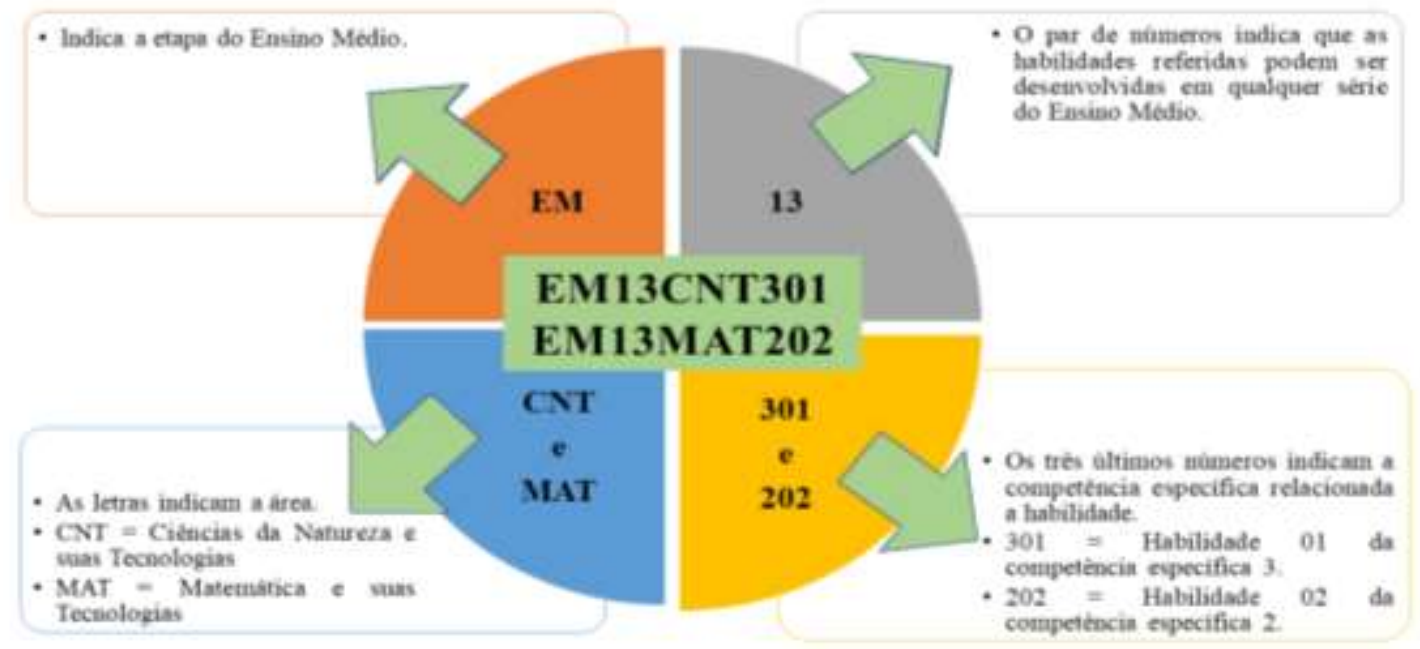

Fonte: Autores, conforme Brasil (2018).

Para a discussão das habilidades serão utilizados os códigos conforme a Figura 1.

\section{As Competências e Habilidades da Área de Ciências da Natureza e suas Tecnologias Estabelecidas na BNCC para o Ensino Médio}

A BNCC estabelece três competências específicas para a área de Ciências da Natureza e suas Tecnologias (Quadro 1), que é composta pelos componentes curriculares de Biologia, Física e Química (Brasil, 2018). 
Quadro 1. Competências Específicas de Ciências da Natureza e suas Tecnologias para o Ensino Médio.

\begin{tabular}{|l|l|}
\hline \multicolumn{2}{|c|}{ Competências específicas } \\
\hline Competência 1 & $\begin{array}{l}\text { Analisar fenômenos naturais e processos tecnológicos, com base nas interações e relações entre matéria } \\
\text { e energia, para propor ações individuais e coletivas que aperfeiçoem processos produtivos, minimizem } \\
\text { impactos socioambientais e melhorem as condições de vida em âmbito local, regional e global. }\end{array}$ \\
\hline Competência 2 & $\begin{array}{l}\text { Analisar e utilizar interpretações sobre a dinâmica da Vida, da Terra e do Cosmos para elaborar } \\
\text { argumentos, realizar previsões sobre o funcionamento e a evolução dos seres vivos e do Universo, e } \\
\text { fundamentar e defender decisões éticas e responsáveis. }\end{array}$ \\
\hline Competência 3 & $\begin{array}{l}\text { Investigar situações-problema e avaliar aplicações do conhecimento científico e tecnológico e suas } \\
\text { implicações no mundo, utilizando procedimentos e linguagens próprios das Ciências da Natureza, para } \\
\text { propor soluções que considerem demandas locais, regionais e/ou globais, e comunicar suas descobertas } \\
\text { e conclusões a públicos variados, em diversos contextos e por meio de diferentes mídias e tecnologias } \\
\text { digitais de informação e comunicação (TDIC). }\end{array}$ \\
\hline
\end{tabular}

Fonte: Autores, conforme Brasil (2018, p.553).

Dentre estas competências, a competência específica 3 faz referência às TDIC em seu enunciado.

A competência específica 3, objetiva que o estudante adquirira a capacidade de pensar cientificamente e, através desse pensamento científico, seja capaz de analisar diferentes situações problema e utilizar os conhecimentos das Ciências da Natureza para propor soluções. Esse pensar demandará do estudante o desenvolvimento de diferentes habilidades que lhe proporcionem uma alfabetização científica que o permita compreender e utilizar as linguagens e procedimentos próprios da área.

Esta competência visa, ainda, o desenvolvimento de maior autonomia quanto ao uso da linguagem científica e a apropriação de procedimentos de coleta e de análise próprios das Ciências da Natureza utilizando as TDIC, assim como as diferentes mídias, para experienciar diálogos em diferentes contextos para públicos variados.

Para o desenvolvimento dessa competência a BNCC estabelece dez habilidades (Quadro 2).

Quadro 2. Habilidades a serem desenvolvidas para o desenvolvimento da competência específica 3 da área de Ciências da Natureza e suas Tecnologias definidas na BNCC.

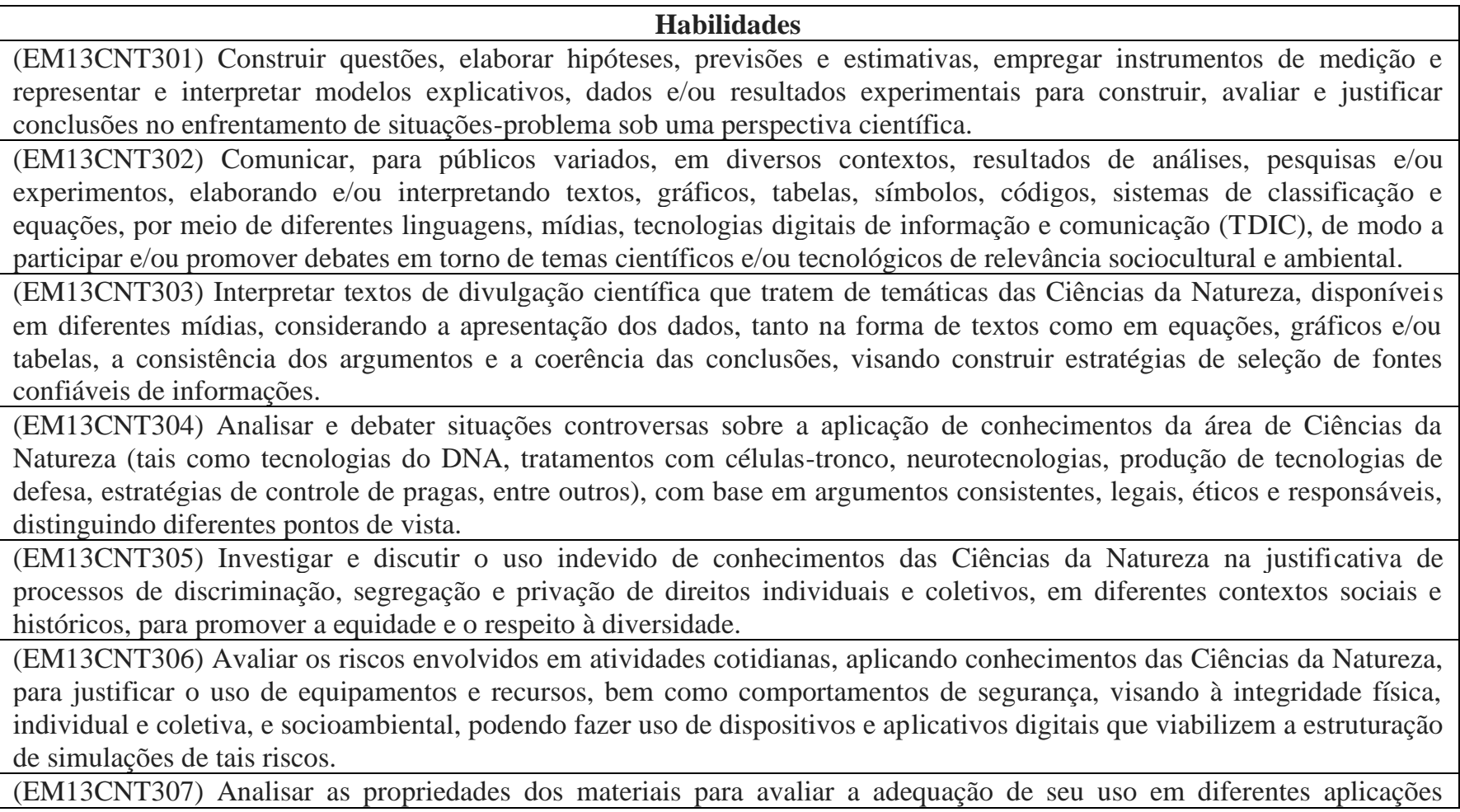


(industriais, cotidianas, arquitetônicas ou tecnológicas) e/ou propor soluções seguras e sustentáveis considerando seu contexto local e cotidiano.

(EM13CNT308) Investigar e analisar o funcionamento de equipamentos elétricos e/ou eletrônicos e sistemas de automação para compreender as tecnologias contemporâneas e avaliar seus impactos sociais, culturais e ambientais.

(EM13CNT309) Analisar questões socioambientais, políticas e econômicas relativas à dependência do mundo atual em relação aos recursos não renováveis e discutir a necessidade de introdução de alternativas e novas tecnologias energéticas e de materiais, comparando diferentes tipos de motores e processos de produção de novos materiais.

(EM13CNT310) Investigar e analisar os efeitos de programas de infraestrutura e demais serviços básicos (saneamento, energia elétrica, transporte, telecomunicações, cobertura vacinal, atendimento primário à saúde e produção de alimentos, entre outros) e identificar necessidades locais e/ou regionais em relação a esses serviços, a fim de avaliar e/ou promover ações que contribuam para a melhoria na qualidade de vida e nas condições de saúde da população.

Fonte: Autores, conforme Brasil (2018, p. 559-560).

A partir das habilidades do Quadro 1 foi produzida no WordClouds uma nuvem de palavras evidenciando os termos mais presentes (Figura 2).

Figura 2. Nuvem de palavras produzida a partir das habilidades a serem desenvolvidas para o desenvolvimento da Competência Específica 3 da área de Ciências da Natureza e suas Tecnologias.

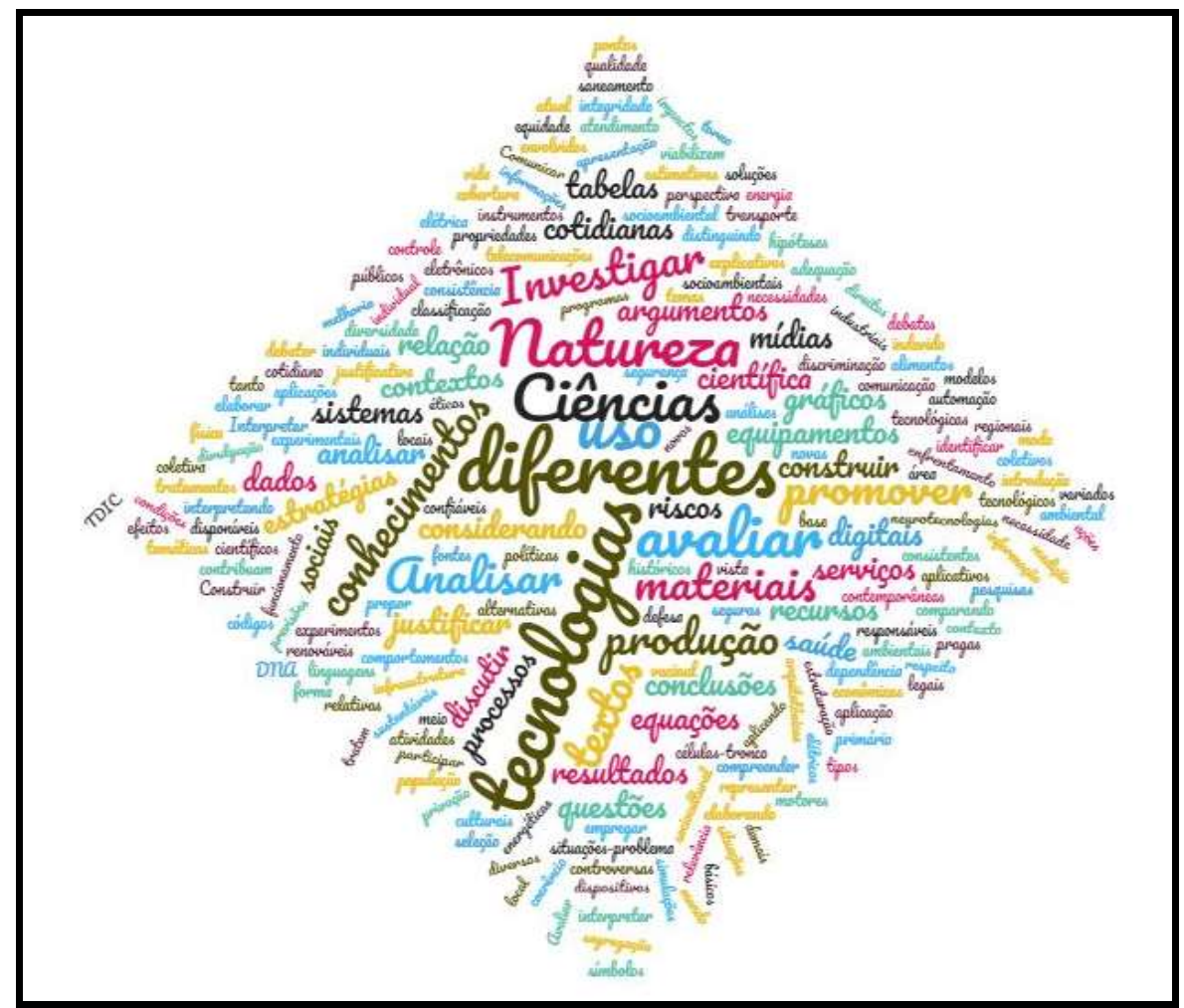

Fonte: Autores.

Conforme a Figura 2, podemos observar que destacam-se as palavras tecnologias, ciências e natureza em um primeiro plano, merecendo, ainda, destaque os termos conhecimentos, avaliar, analisar e investigar como as palavras mais presentes nas habilidades relacionadas à Competência 3.

Podemos observar nas habilidades estabelecidas para o desenvolvimento da competência específica 3 o foco no desenvolvimento do pensamento científico do estudante permitindo que ele seja capaz de enfrentar situações problema com um olhar científico tendo, desta forma, a habilidade para construir, avaliar e justificar conclusões considerando a apresentação de 
dados, a consistência de argumentos e a coerência de conclusões e, assim, debater temas científicos e tecnológicos relevantes (EM13CNT301, EM13CNT302, EM13CNT303). Destacam-se, ainda, as habilidades EM13CNT304 e EM13CNT305, que tratam sobre a capacidade de discutir o uso indevido de conhecimentos das Ciências da Natureza para o desrespeito à diversidade, assim como, discutir situações controversas, com base em argumentos éticos e consistentes, sobre a aplicação de conhecimentos desta área a questões como tratamento com células tronco, tecnologias de DNA e produção de armamentos, por exemplo.

Para o desenvolvimento do pensar científico estabelecido na competência específica 3, se faz necessário que o estudante desenvolva a habilidade de "construir questões, elaborar hipóteses, previsões e estimativas" conforme a habilidade EM13CNT301 (Brasil, 2018, p. 559). O estudante deve, desta forma, ser alfabetizado cientificamente para que, juntamente com uma alfabetização matemática, tenha a habilidade de interpretar textos de divulgação científica, sobre Ciências da Natureza, sendo capaz de representar e interpretar modelos explicativos, dados e/ou resultados experimentais, interpretando gráficos, tabelas, símbolos, códigos, sistemas de classificação e equações conforme destacado nas habilidades EM13CNT301, EM13CNT302 e EM13CNT303.

A partir das habilidades discutidas anteriormente, o estudante poderá, com a mediação do professor, trabalhar no desenvolvimento de outras habilidades relacionadas a aplicação dos conhecimentos das Ciências da Natureza para diferentes finalidades como avaliar riscos em atividades cotidianas (EM13CNT306), propor soluções seguras e sustentáveis para uso de materiais de acordo com as suas propriedades (EM13CNT307), discutir tecnologias energéticas e de materiais (EM13CNT309), investigar e analisar questões relacionadas a energia elétrica, saneamento básico, produção de alimentos, transporte, vacinas, entre outras questões referentes a serviços básicos e questões de infraestrutura com foco na qualidade de vida da população e tendo como referência demandas locais e/ou regionais sobre esses temas (EM13CNT310).

Quanto às TDIC, um dos focos principais da competência específica 3 é a de comunicar descobertas e conclusões a públicos variados. Com essa finalidade, a habilidade EM13CNT302 trata da comunicação de resultados de análises, pesquisas ou experimentos utilizando diferentes mídias para a comunicação em diversos contextos.

As diferentes mídias estão presentes nas orientações de desenvolvimento das habilidades dos estudantes tanto para buscar informações que tratem das temáticas das Ciências da Natureza em variados tipos de mídia assim como utilizar tais mídias para comunicar-se com diferentes públicos divulgando descobertas e conclusões realizadas em seus estudos.

$\mathrm{Na}$ atualidade, por meio da internet e das TDIC, as pessoas se deparam com uma quantidade enorme de informações das quais, muitas vezes, encontram-se notícias falsas (fake News). Quanto a esta temática, a BNCC traz na habilidade EM13CNT303 um destaque especial para o tema quando destaca sobre o desenvolvimento da capacidade de "construir estratégias de seleção de fontes confiáveis de informações", o que é uma habilidade fundamental para o exercício pleno da cidadania.

\section{As Competências e Habilidades da Área de Matemática e suas Tecnologias Estabelecidas na BNCC para o Ensino Médio}

Para a área de conhecimento "Matemática e suas tecnologias", a BNCC estabelece cinco competências específicas, que são apresentadas no Quadro 3. 
Quadro 3. Competências Específicas de Matemática e suas Tecnologias para o Ensino Médio.

\begin{tabular}{|l|l|}
\hline \multicolumn{2}{|c|}{ Competências específicas } \\
\hline Competência 1 & $\begin{array}{l}\text { Utilizar estratégias, conceitos e procedimentos matemáticos para interpretar situações em diversos } \\
\text { contextos sejam atividades cotidianas, sejam fatos das Ciências da Natureza e Humanas das questões } \\
\text { socioeconômicas ou tecnológicas, divulgados por diferentes meios, de modo a contribuir para uma } \\
\text { formação geral. }\end{array}$ \\
\hline Competência 2 & $\begin{array}{l}\text { Propor ou participar de ações para investigar desafios do mundo contemporâneo e tomar decisões éticas e } \\
\text { socialmente responsáveis, com base na análise de problemas sociais, como os voltados a situações de } \\
\text { saúde, sustentabilidade, das implicações da tecnologia no mundo do trabalho, entre outros, mobilizando e } \\
\text { articulando conceitos, procedimentos e linguagens próprios da Matemática. }\end{array}$ \\
\hline Competência 3 & $\begin{array}{l}\text { Utilizar estratégias, conceitos, definições e procedimentos matemáticos para interpretar, construir } \\
\text { modelos e resolver problemas em diversos contextos, analisando a plausibilidade dos resultados e a } \\
\text { adequação das soluções propostas, de modo a construir argumentação consistente. }\end{array}$ \\
\hline Competência 4 & $\begin{array}{l}\text { Compreender e utilizar, com flexibilidade e precisão, diferentes registros de representação matemáticos } \\
\text { (algébrico, geométrico, estatístico, computacional etc.), na busca de solução e comunicação de resultados } \\
\text { de problemas. }\end{array}$ \\
\hline Competência 5 & $\begin{array}{l}\text { Investigar e estabelecer conjecturas a respeito de diferentes conceitos e propriedades matemáticas, } \\
\text { empregando estratégias e recursos, como observação de padrões, experimentações e diferentes } \\
\text { tecnologias, identificando a necessidade, ou não, de uma demonstração cada vez mais formal na } \\
\text { validação das referidas conjecturas. }\end{array}$ \\
\hline
\end{tabular}

Fonte: Autores, conforme Brasil (2018, p. 531)

A seguir são destacadas as competências e as habilidades que abordam sobre as TDIC.

$\mathrm{Na}$ competência específica 1 é previsto que os estudantes compreendam os conceitos matemáticos em diversos contextos de sua realidade podendo aplicá-los a outras áreas do conhecimento. Nesta competência as habilidades que contemplam as TDIC são destacadas no Quadro 4

Quadro 4. Habilidades a serem desenvolvidas para o desenvolvimento da competência específica 1 da área de Matemática e suas Tecnologias definidas na BNCC.

\section{Habilidades}

(EM13MAT101) Interpretar criticamente situações econômicas, sociais e fatos relativos às Ciências da Natureza que envolvam a variação de grandezas, pela análise dos gráficos das funções representadas e das taxas de variação, com ou sem apoio de tecnologias digitais.

(EM13MAT103) Interpretar e compreender textos científicos ou divulgados pelas mídias, que empregam unidades de medida de diferentes grandezas e as conversões possíveis entre elas, adotadas ou não pelo Sistema Internacional (SI), como as de armazenamento e velocidade de transferência de dados, ligadas aos avanços tecnológicos.

Fonte: Autores, conforme Brasil (2018, p. 533).

Ambas as habilidades retratam a interpretação de grandezas utilizadas para expressar dados, sejam eles qualitativos ou quantitativos. A primeira habilidade sugere de modo claro quanto ao uso das tecnologias digitais para a análise da variação de duas grandezas em gráficos das funções. Na segunda é descrito quanto aos avanços tecnológicos no qual é destacado as novas unidades que são o armazenamento de dados e de distâncias astronômicas e microscópicas.

A competência 2 destaca quanto ao desenvolvimento da habilidade de proposição e participação em ações relativas a temáticas contemporâneas, como o impacto das tecnologias no mundo do trabalho, assim como, quanto a outras questões sociais, de modo que o estudante seja capaz de mobilizar conceitos matemáticos para compreender tais temas e propor ações éticas e responsáveis para a resolução destes. As habilidades estabelecidas para o desenvolvimento desta competência, que apresentam TDIC, são destacadas no Quadro 5. 
Quadro 5. Habilidades a serem desenvolvidas para o desenvolvimento da competência específica 2 da área de Matemática e suas Tecnologias definidas na BNCC.

\begin{tabular}{l} 
Habilidades \\
\hline (EM13MAT202) Planejar e executar pesquisa amostral sobre questões relevantes, usando dados coletados diretamente ou em \\
diferentes fontes, e comunicar os resultados por meio de relatório contendo gráficos e interpretação das medidas de tendência \\
central e das medidas de dispersão (amplitude e desvio padrão), utilizando ou não recursos tecnológicos. \\
(EM13MAT203) Aplicar conceitos matemáticos no planejamento, na execução e na análise de ações envolvendo a utilização \\
de aplicativos e a criação de planilhas (para o controle de orçamento familiar, simuladores de cálculos de juros simples e \\
compostos, entre outros), para tomar decisões.
\end{tabular}

Fonte: Autores, conforme Brasil (2018, p. 534).

As habilidades referentes a competência específica 2 destacam sobre a utilização das tecnologias digitais. A habilidade EM13MAT202 trata da possibilidade de uso de recursos tecnológicos para o planejamento e execução de pesquisas amostrais, envolvendo para esta finalidade alguns conceitos de Estatística, e para a comunicação dos resultados através de relatórios com a interpretação gráfica dos dados. A habilidade EM13MAT203 aborda o planejamento e a execução de ações baseadas na aplicação de conceitos matemáticos para a tomada de decisões. Para este fim, propõe-se a utilização de TDIC, como planilhas eletrônicas e aplicativos de modo geral, para a execução de tais tarefas.

A Competência específica 3 aborda o uso de conceitos matemáticos para resolução de problemas em diversos contextos e a construção de argumentações consistentes. As habilidades que destacam quanto ao uso das TDIC, referentes a esta competência, são apresentadas no Quadro 6.

Quadro 6. Habilidades a serem desenvolvidas para o desenvolvimento da competência específica 3 da área de Matemática e suas Tecnologias definidas na BNCC.

\section{Habilidades}

(EM13MAT301) Resolver e elaborar problemas do cotidiano, da Matemática e de outras áreas do conhecimento, que envolvem equações lineares simultâneas, usando técnicas algébricas e gráficas, com ou sem apoio de tecnologias digitais. (EM13MAT302) Construir modelos empregando as funções polinomiais de $1^{\circ}$ ou $2^{\circ}$ graus, para resolver problemas em contextos diversos, com ou sem apoio de tecnologias digitais.

(EM13MAT306) Resolver e elaborar problemas em contextos que envolvem fenômenos periódicos reais (ondas sonoras, fases da lua, movimentos cíclicos, entre outros) e comparar suas representações com as funções seno e cosseno, no plano cartesiano, com ou sem apoio de aplicativos de álgebra e geometria.

(EM13MAT307) Empregar diferentes métodos para a obtenção da medida da área de uma superfície (reconfigurações, aproximação por cortes etc.) e deduzir expressões de cálculo para aplicá-las em situações reais (como o remanejamento e a distribuição de plantações, entre outros), com ou sem apoio de tecnologias digitais.

(EM13MAT309) Resolver e elaborar problemas que envolvem o cálculo de áreas totais e de volumes de prismas, pirâmides e corpos redondos em situações reais (como o cálculo do gasto de material para revestimento ou pinturas de objetos cujos formatos sejam composições dos sólidos estudados), com ou sem apoio de tecnologias digitais.

Fonte: Autores, conforme Brasil (2018, p. 536-537).

As cinco habilidades apresentadas no quadro 4 sugerem a possibilidade de utilização das tecnologias digitais para o ensino de conceitos matemáticos. As TDIC são sugeridas como ferramentas de apoio para a elaboração e resolução de problemas do cotidiano da Álgebra e da Geometria. Por fim, na última habilidade, é destacado quanto ao reconhecimento e utilização de algoritmos e fluxogramas.

A Competência específica 4 aborda a importância e necessidade dos registros de representação matemáticos, dentre eles o computacional, que devem ser compreendidos e interpretados visando a solução e a comunicação de resultados de problemas.

As habilidades relacionadas a esta competência são exibidas no Quadro 7. 
Quadro 7. Habilidades a serem desenvolvidas para o desenvolvimento da competência específica 4 da área de Matemática e suas Tecnologias definidas na BNCC.

\begin{tabular}{l} 
Habilidades \\
\hline (EM13MAT401) Converter representações algébricas de funções polinomiais de $1^{\circ}$ grau em representações geométricas no \\
plano cartesiano, distinguindo os casos nos quais o comportamento é proporcional, recorrendo ou não a softwares ou \\
aplicativos de álgebra e geometria dinâmica. \\
(EM13MAT402) Converter representações algébricas de funções polinomiais de $2^{\circ}$ grau em representações geométricas no \\
plano cartesiano, distinguindo os casos nos quais uma variável for diretamente proporcional ao quadrado da outra, \\
recorrendo ou não a softwares ou aplicativos de álgebra e geometria dinâmica, entre outros materiais. \\
(EM13MAT403) Analisar e estabelecer relações, com ou sem apoio de tecnologias digitais, entre as representações de \\
funções exponencial e logarítmica expressas em tabelas e em plano cartesiano, para identificar as características \\
fundamentais (domínio, imagem, crescimento) de cada função. \\
(EM13MAT404) Analisar funções definidas por uma ou mais sentenças (tabela do Imposto de Renda, contas de luz, água, \\
gás etc.), em suas representações algébrica e gráfica, identificando domínios de validade, imagem, crescimento e \\
decrescimento, e convertendo essas representações de uma para outra, com ou sem apoio de tecnologias digitais. \\
(EM13MAT405) Utilizar conceitos iniciais de uma linguagem de programação na implementação de algoritmos escritos em \\
linguagem corrente e/ou matemática. \\
(EM13MAT406) Construir e interpretar tabelas e gráficos de frequências com base em dados obtidos em pesquisas por \\
amostras estatísticas, incluindo ou não o uso de softwares que inter-relacionem estatística, geometria e álgebra.
\end{tabular}

Fonte: Autores, conforme Brasil (2018, p. 539).

Em relação à competência 4, são apresentadas seis habilidades a serem desenvolvidas com relação às tecnologias digitais. As habilidades EM13MAT401 e EM13MAT402 abordam o possível uso de softwares ou aplicativos de álgebra e geometria dinâmica para a conversão de representações algébricas de funções polinomiais. As EM13MAT403 e EM13MAT404 destacam sobre a análise de funções e das diferentes representações com a possibilidade de utilização de TDIC para identificação de características fundamentais de cada função estudada. Na habilidade EM13MAT405 é proposto o uso da linguagem de programação e implementação de algoritmos na linguagem corrente e/ou matemática. Na EM13MAT406 é proposta a construção e interpretação de tabelas e gráficos de frequências obtidas em pesquisas amostrais com a possibilidade da utilização de softwares relacionando a Estatística com outras unidades de conhecimento da área da Matemática.

A Competência específica 5, busca que o estudante tenha capacidade de fazer conjecturas de diferentes conceitos e propriedades matemáticas, e a tecnologias digitais é proposta como um recurso para esta investigação e estabelecimento de conjecturas, não apenas com uma argumentação empírica, mas buscando obter cada vez mais argumentos formais. O conjunto de habilidades estabelecidas que abordam as TDIC estão organizadas no Quadro 8.

Quadro 8. Habilidades a serem desenvolvidas para o desenvolvimento da competência específica 5 da área de Matemática e suas Tecnologias definidas na BNCC.

\section{Habilidades}

(EM13MAT503) Investigar pontos de máximo ou de mínimo de funções quadráticas em contextos envolvendo superfícies, Matemática Financeira ou Cinemática, entre outros, com apoio de tecnologias digitais.

(EM13MAT505) Resolver problemas sobre ladrilhamento do plano, com ou sem apoio de aplicativos de geometria dinâmica, para conjecturar a respeito dos tipos ou composição de polígonos que podem ser utilizados em ladrilhamento, generalizando padrões observados.

(EM13MAT509) Investigar a deformação de ângulos e áreas provocada pelas diferentes projeções usadas em cartografia (como a cilíndrica e a cônica), com ou sem suporte de tecnologia digital.

(EM13MAT510) Investigar conjuntos de dados relativos ao comportamento de duas variáveis numéricas, usando ou não tecnologias da informação, e, quando apropriado, levar em conta a variação e utilizar uma reta para descrever a relação observada. 
$\mathrm{Na}$ competência 5 são apresentadas quatro habilidades que destacam quanto à utilização das TDIC. As EM13MAT503 e EM13MAT509 apontam a TDIC como um suporte para contribuir para a investigação dos conceitos matemáticos. A EM13MAT505 sugere a possibilidade do uso de aplicativos de geometria dinâmica para a resolução de problemas e elaboração de conjecturas para a generalização de padrões observados. Na habilidade EM13MAT510 aborda sobre a investigação de conjunto de dados com a possibilidade do uso de TDIC.

Na Figura 3 é apresentada a nuvem de palavras criada no Wordclouds produzida a partir das habilidades já destacadas nos quadros anteriores, a serem desenvolvidas para o desenvolvimento das Competências Específicas da área de Matemática e suas Tecnologias.

Figura 3. Nuvem de palavras das habilidades relacionadas às tecnologias digitais na BNCC.

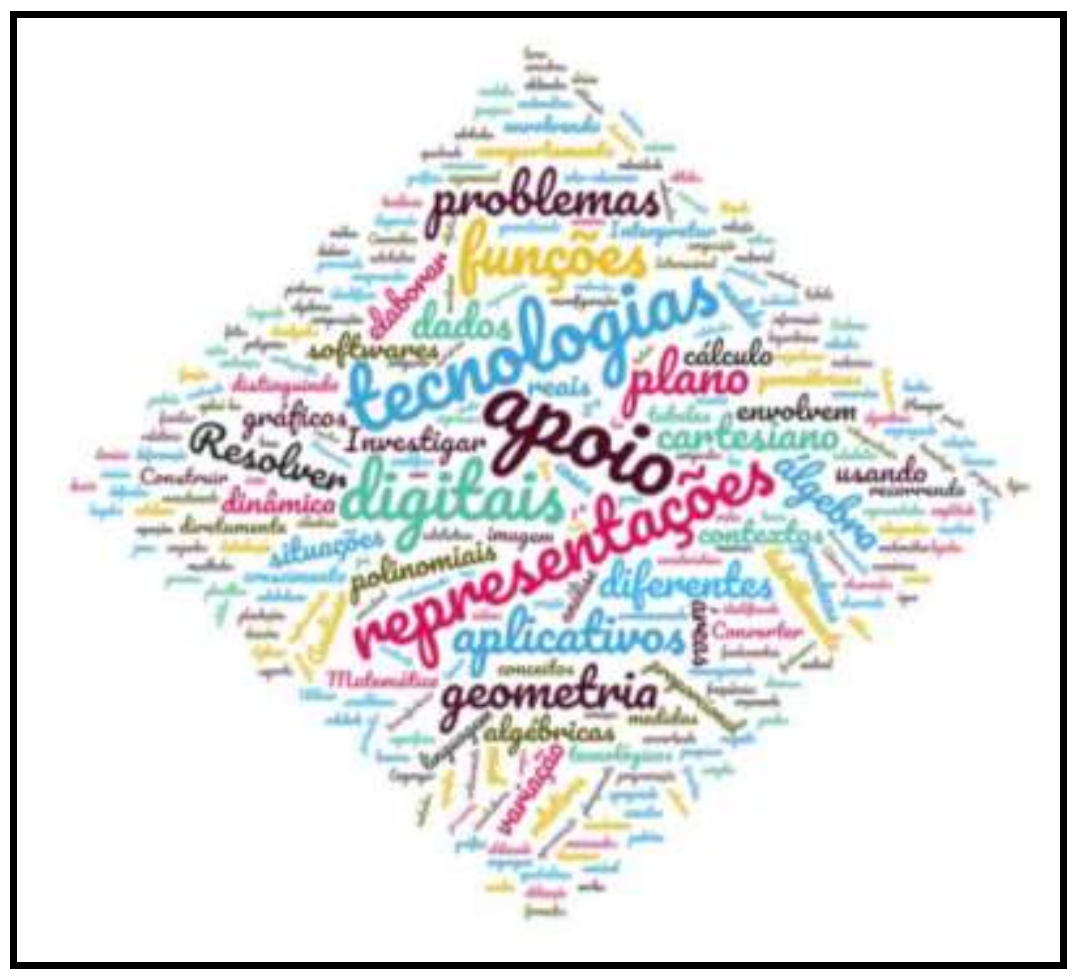

Fonte: Autores.

$\mathrm{Na}$ análise da Figura 3 pode-se perceber a evidência com relação a sugestão do apoio às tecnologias digitais nas habilidades a serem desenvolvidas para a área da Matemática no qual é destacado o trabalho com as diferentes representações e a resolução de problemas, além disso é possível verificar quanto aos conceitos específicos, em relação a geometria, as funções e a álgebra.

\section{O uso das TDIC como Ferramentas Facilitadoras para o Desenvolvimento das Demais}

\section{Competências e Habilidades}

As TDIC podem contribuir para a realização de diversas atividades nas diversas áreas do conhecimento e, deste modo, possuem muitas potencialidades no desenvolvimento dos conceitos a serem trabalhados em sala de aula. Nesta perspectiva, Brasil (2018) destaca que as competências e as habilidades podem propiciar aos estudantes: 
- buscar dados e informações de forma crítica nas diferentes mídias, inclusive as sociais, analisando as vantagens do uso e da evolução da tecnologia na sociedade atual, como também seus riscos potenciais;

- apropriar-se das linguagens da cultura digital, dos novos letramentos e dos multiletramentos para explorar e produzir conteúdos em diversas mídias, ampliando as possibilidades de acesso à ciência, à tecnologia, à cultura e ao trabalho;

- usar diversas ferramentas de software e aplicativos para compreender e produzir conteúdos em diversas mídias, simular fenômenos e processos das diferentes áreas do conhecimento, e elaborar e explorar diversos registros de representação matemática; e

- utilizar, propor e/ou implementar soluções (processos e produtos) envolvendo diferentes tecnologias, para identificar, analisar, modelar e solucionar problemas complexos em diversas áreas da vida cotidiana, explorando de forma efetiva o raciocínio lógico, o pensamento computacional, o espírito de investigação e a criatividade. (p. 474475)

Outro aspecto que merece destaque são as potencialidades do uso das diferentes TDIC como ferramentas facilitadoras para o processo de ensino-aprendizagem de diferentes conceitos relacionados a Matemática e a Ciências da Natureza e suas Tecnologias podendo, desta forma, ser empregadas pelo docente para o desenvolvimento das demais competências e habilidades.

Devido as potencialidades das TDIC, inúmeros estudos vêm sendo realizados sobre a sua utilização dentro do processo de ensino-aprendizagem de Matemática e Ciências da Natureza (Delamuta et al., 2020; Costa \& Prado, 2015).

Tais estudos envolvem, por exemplo, temas como aprendizagem móvel (do inglês mobile learning ou m-learning) (Almeida et al., 2015; Resende \& Müller, 2018), onde merecem destaque estudos sobre o desenvolvimento e uso de aplicativos em atividades de ensino e aprendizagem de conceitos da Matemática e das Ciências da Natureza (Silva et al., 2015; Rosa \& Roehrs, 2020; Teixeira et al., 2017).

Ainda é possível destacar sobre a contribuição de ferramentas digitais tais como o Kahoot, Piktochart e Pixton recursos que abordam jogos, infográficos e histórias em quadrinhos que potencializam o processo de ensino e de aprendizagem. (Ritter et al, 2020).

O destaque dado nas diferentes competências e habilidades abordadas neste estudo a resolução de problemas nos leva, ainda, a destacar as potencialidades do emprego de metodologias ativas, como a Aprendizagem Baseada em Problemas (PBL, do inglês Problem-Based Learning) e a Aprendizagem Baseada em Projetos, que podem permitir que através da resolução de problemas ou do trabalho em projetos o estudante possa, além de desenvolver tais competências e habilidades, desenvolver ainda outras competências como iniciativa, criatividade, criticidade reflexiva, capacidade de autoavaliação e cooperação para trabalhar em equipe (Lovato et al., 2018).

Os estudos citados são alguns exemplos de como as TDIC podem auxiliar na construção de diferentes conhecimentos possibilitando o desenvolvimento de diferentes habilidades e competências.

\section{Caminhos a Serem Percorridos para o Uso de TDIC na Educação: Desafios e Limitações}

Inúmeras são as potencialidades das TDIC na educação. Da mesma forma, são grandes os desafios e limitações para o bom aproveitamento das Tecnologias Digitais.

Dentro das TDIC merecem destaque como temáticas emergentes, com grande potencial de utilização na educação, o emprego da Inteligência Artificial e Realidade Aumentada, assim como, o desenvolvimento e utilização de jogos digitais em estratégias de Gamificação que podem ser aplicados ao processo de ensino-aprendizagem visando a compreensão de conceitos e o desenvolvimento de Competências e Habilidades nas diferentes áreas do conhecimento.

A utilização da Inteligência Artificial (IA) vem ocorrendo em várias áreas. A automatização de serviços, transações eletrônicas, temas de localização, automação industrial, uso de bots em redes sociais e canais de atendimento são alguns exemplos da crescente aplicação e importância da IA no mundo em que vivemos (Tavares et al., 2020). 
Na educação, segundo Tavares et al. (2020), os Sistemas de Tutores Inteligentes são uma das principais aplicações de IA na Educação. Todavia, seu emprego possui inúmeras outras possibilidades. Conforme os autores

Acredita-se que ferramentas inteligentes possam trabalhar como apoio na coleta de informações durante os processos de ensino-aprendizagem em ambientes educacionais. Desta forma, pode auxiliar na seleção de conteúdo e subsidiar métodos de avaliação discente. E esse suporte inteligente de informações poderá gerir estratégias de modo identificar padrões, realizar diagnósticos e intervir na comunicação entre professor e aluno para subsidiar tomadas de decisão no processo de ensino-aprendizagem (Tavares et al., 2020, p. 48711-48712).

Dentro das potencialidades das TDIC, temos também a utilização da Realidade Aumentada (RA) como um importante instrumento que pode contribuir para a aprendizagem dos estudantes. A RA possui como características a "combinação de elementos do mundo real e virtual, a representação dos elementos em 3D e a interação em tempo real" (Del-Moral \& NeiraPiñeiro, 2020, p. 725), assim como, possui também a capacidade de contribuir para transformar uma ideia abstrata em algo tangível para os estudantes (Villalustre \& Del-Moral, 2016).

Diante das potencialidades da RA, estudos vêm sendo realizados visando utilizar os recursos de Realidade Aumentada com a finalidade de potencializar livros para fins didáticos empregando recursos como elementos gráficos e sonoros para facilitar a aprendizagem (Galvão \& Zorzal, 2012, Vahldick \& Bittencourt, 2019).

Outra possibilidade trazida pelas Tecnologias Digitais é a utilização de jogos digitais e o emprego da "Gamificação" (gamification) para despertar e incentivar o interesse dos estudantes para alcançar objetivos educacionais ou, ainda, profissionais e pessoais. A Gamificação baseia-se na aplicação de princípios, mecânicas e design de jogos e utiliza recursos como rankings, pontuações e desafios, assim como, a ludicidade dos jogos, como os de videogame, para construir estratégias motivacionais que contribuam para o aprendizado dos estudantes (Campos \& Lastória, 2020).

A inteligência artificial está presente nos diferentes jogos digitais e o seu emprego associado aos games possui grande potencial na educação. Conforme Campos \& Lastória (2020)

A inteligência artificial está envolvida na produção de interações que despertam o interesse e o engajamento dos jogadores na superação dos desafios propostos. Sua principal função é produzir um efeito lúdico e imersivo, proporcionando desafios com diferentes níveis de adaptação, nem muito fáceis nem muito difíceis, de modo a entrelaçar esforço e divertimento, fazendo o jogador/aluno sentir prazer ao mesmo tempo em que se esforça para executar a tarefa programada (Campos \& Lastória, 2020, p. 7).

Apesar das inúmeras potencialidades, também são grandes os desafios e limitações para o emprego das TDIC para o aprendizado dentro e fora de sala de aula. A formação docente e o acesso à internet de banda larga são algumas das questões a serem enfrentadas para que o potencial das Tecnologias Digitais possa ser plenamente aproveitado (Fonseca, 2013; Jacon et al., 2014).

\section{Considerações Finais}

A BNCC do Ensino Médio apresenta um ensino centrado no desenvolvimento de competências e habilidades na qual destaca a proposta de um currículo possibilitando uma orientação aos professores e, dentro desta orientação, é importante destacar a implementação da utilização das TDIC na Educação Básica para a preparação dos estudantes para a vida cotidiana e para o mundo do trabalho.

Nesse sentido, pudemos verificar neste estudo o papel de destaque das TDIC na BNCC do Ensino Médio, nas áreas de Ciências da Natureza e Matemática e suas Tecnologias, e a importância de sua utilização nos processos de ensino e aprendizagem para o desenvolvimento de diferentes competências e habilidades. Na área de Ciências da Natureza e suas Tecnologias destacou-se como um dos objetivos da utilização das TDIC o uso das diferentes mídias para comunicar, em 
diversos contextos, descobertas, resultados e conclusões sobre temas científicos. Merece também destaque a preocupação com que o estudante desenvolva a habilidade de seleção de fontes e informações confiáveis. Com relação a área da Matemática e suas Tecnologias é evidenciada na BNCC o uso de tecnologias digitais como apoio, bem como o uso de softwares e aplicativos e a linguagem de programação para o desenvolvimento das habilidades e compreensão dos conceitos.

Desta forma, concluímos que as TDIC são importantes instrumentos dentro do processo de ensino e aprendizagem contribuindo para o desenvolvimento das competências e habilidades de ambas as áreas de conhecimento abordadas neste estudo.

Por fim, com base no que foi tratado neste estudo, esperamos que as discussões e reflexões trazidas possam subsidiar o docente em seu papel de mediador de um processo de ensino e aprendizagem que possibilite ao estudante o desenvolvimento das competências e habilidades estabelecidas na BNCC para as áreas de Ciências da Natureza e Matemática e suas Tecnologias. Esperamos, desta forma, contribuir para que o professor possa, com o seu fazer educação, possibilitar que "os estudantes possam tornar-se agentes de transformações - para melhor - do mundo em que vivemos" (Chassot, 2017, p.84).

Como trabalhos futuros tenciona-se investigar o uso pedagógico das TDIC para o ensino das áreas de Ciências da Natureza e Matemática, a fim de contemplar as habilidades e competências propostas na BNCC.

\section{Agradecimentos}

Os autores agradecem o apoio da Coordenação de Aperfeiçoamento de Pessoal de Nível Superior - Brasil (CAPES), para a realização da pesquisa.

\section{Referências}

Almeida, M., \& Silva, M. (2011). Currículo, tecnologia e cultura digital: espaços e tempos de web currículo. Revista e-Curriculum, 7(1). 1-19.

Almeida, R. R., Araújo Jr., C. F., \& França, M. P. (2015). O uso do tablet para a representação de conceitos de genética: proposta e análise com base na Teoria da Atividade. Renote - Revista Novas Tecnologias na Educação, 13(1), 1-11.

Almeida, M. E. B. (2007). Tecnologias digitais na educação: o futuro é hoje. Recuperado de https://etic2008.files.wordpress.com/200 8/11/pucspmariaelizabeth.pdf.

Almeida, M. E. B., \& Valente, J. A. (2011). Tecnologias e Currículo: trajetórias convergentes ou divergentes? Paulus.

Baranauskas, M. $\quad$ C. $\quad$ C., $\quad \& \quad$ Valente, J. A. (2013). Editorial. Tecnologias, Sociedade e Conhecimento, $1 \quad$ (1), 1-5. https://www.nied.unicamp.br/revista/index.php/tsc/article/download/118/96/.

Brasil. (1996). Lei $n^{\circ}$ 9.394, de 20 de dezembro de 1996. Estabelece as diretrizes e bases da educação nacional. Diário Oficial da União, Brasília, 23 de dezembro de 1996. http://www.planalto.gov.br/ccivil_03/leis/L9394.htm.

Brasil. (1998) Ministério da Educação Fundamental. Parâmetros Curriculares Nacionais: terceiro e quarto ciclos do ensino fundamental: introdução aos parâmetros curriculares nacionais. Brasília, 1998.

Brasil. (2018). Ministério da Educação. Base Nacional Comum Curricular: Educação é a base. Brasília: MEC, 2018. http://basenacionalcomum.mec.gov.br/images/BNCC_EI_EF_110518_versaofinal_site.pdf.

Campos, L. F. A. A., \& Lastória, L. A. C. N. (2020). Semiformação e inteligência artificial no ensino. Pro-Posições, 31, e20180105, 2020. http://dx.doi.org/10.1590/1980-6248-2018-0105.

Chassot, A. (2017). Alfabetização científica: questões e desafios para a educação. (7a ed.), Ed. Unijuí.

Costa, N. M. L., \& Prado, M. E. B. B. (2015). A Integração das Tecnologias Digitais ao Ensino de Matemática: desafio constante no cotidiano escolar do professor. Perspectivas da Educação Matemática, 18 (16), 99-120.

Costa, S. R. S., Duqueviz, B. C., \& Pedroza, R. L. C. (2015). Tecnologias Digitais como instrumentos mediadores da aprendizagem dos nativos digitais. Revista Quadrimestral da Associação Brasileira de Psicologia Escolar e Educacional, 19 (3), 2015, 603-610. https://doi.org/10.1590/2175$3539 / 2015 / 0193912$.

Delamuta, B. H., Assai, N. D. S., \& Sanchez Júnior, S. L. (2020). O ensino de Química e as TDIC: uma revisão sistemática de literatura e uma proposta de webquest para o ensino de Ligações Químicas. Research, Society and Development, 9 (9), e149996839, 2020. https://doi.org/10.33448/rsd-v9i9.6839. 
Research, Society and Development, v. 10, n. 1, e59510112157, 2021

(CC BY 4.0) | ISSN 2525-3409 | DOI: http://dx.doi.org/10.33448/rsd-v10i1.12157

Del-Moral, M. E., \& Neira-Piñeiro, M. R. (2020). Realidade Aumentada e literatura infantil na Educação Infantil. Debates em Educação, 12 (27), 2020. $10.28998 / 2175-6600.2020 v 12 \mathrm{n} 27 \mathrm{p} 724-743$

Fonseca, A. G. M. F. (2013). Aprendizagem, mobilidade e convergência: Mobile Learning com Celulares e Smartphones. Revista Eletrônica do Programa de Pós-Graduação em Mídia e Cotidiano, (2), 163-181.

Galvão, M. A., \& Zorzal, E. R. (2012). Aplicações Móveis com Realidade Aumentada para Potencializar Livros. RENOTE - Revista Novas Tecnologias na Educação, $10(1), 1-10$.

Gil, A. C. (2008). Métodos e técnicas de pesquisa social. (6a ed.), Atlas.

Jacon, L. S. C., Oliveira, A. C. G., Marti, E. A. L. M., \& Mello, I. C. (2014). Os formadores de professores e o desafio em potencializar o ensino de conhecimentos químicos com a incorporação dos dispositivos móveis. Investigaçães em Ensino de Ciências, 19(1), 77-89.

Jordão, T. C. (2009). Formação de educadores: a formação do professor para a educação em um mundo digital. In: Tecnologias digitais na educação. MEC.

Lakatos, E. M.; \& Marconi, M. A. (2011). Metodologia científica. (6a ed.), Atlas.

Lovato, F. L., Michelotti, A; Silva, C. B., \& Loretto, E. L. S. (2018). Metodologias Ativas de Aprendizagem: Uma Breve Revisão. Acta Scientiae, 20 (2), 154171.

Pereira A. S., et al. (2018). Metodologia da pesquisa científica. Ed. UAB/NTE/UFSM. https://repositorio.ufsm.br/bitstream/handle/1/15824/Lic_Comput acao_Metodologia-Pesquisa-Cientifica.pdf?sequence=1.

Resende, B., \& Müller, T. J. (2018). Mobile-learning: aprendizagem matemática por meio de realidade aumentada. \# Tear: Revista de Educação, Ciência e Tecnologia, 7 (2), 2018. https://doi.org/10.35819/tear.v7.n2.a3187.

Ritter, D., Fusiger, J., Bulegon, A. M., \& Nunes, J. (2020). Uma experiência com o uso de Tecnologias Digitais no estudo de Quadriláteros. Ensino da Matemática em Debate, 7 (2), 180-199. https://doi.org/10.23925/2358-4122.2020v7i2p180-199.

Rosa, A. S., \& Roehrs, R. (2020). Aplicativos móveis: algumas possibilidades para o ensino de Química. Research, Society and Development, 9 (8), e33984955, 2020. http://dx.doi.org/10.33448/rsd-v9i8.4955.

Silva, P. F., Silva, T. P., \& Silva, G. N. (2015). StudyLab: Construção e Avaliação de um aplicativo para auxiliar o Ensino de Química por professores da Educação Básica. Revista Tecnologias na Educação, 7 (13), 1-8.

Tavares, L. A., Meira, M. C., \& Amaral, S. F. (2020). Inteligência Artificial na Educação: Survey. Brazilian Journal of Development, 6 (7), 48699-48714, 2020. 10.34117/bjdv6n7-496.

Teixeira, R. M., Victer, E. F., \& Silva, J. C. (2017). Ensino de Geometria: Uma possibilidade por meio do aplicativo "GeoMetriCraft". Revista Eletrônica do Instituto de Humanidades, 18 (44), 88-108.

Vahldick, A., \& Bittencourt, D. (2019). Uma Experiência em Sala de Aula usando um Livro Didático convertido para um Livro Aumentado. Brazilian Symposium on Computers in Education (Simpósio Brasileiro de Informática na Educação - SBIE), 30 (1), 654. http://dx.doi.org/10.5753/cbie.sbie.2019.654.

Valente, J. A. (2015). As tecnologias digitais de informação e comunicação e as mudanças no processo de ensino e aprendizagem no ensino superior. In: Rocha, M. M. et al. Educação a distância: tecendo redes de saberes nas práticas de educação a distância: campo de experiências. 1. São João del-Rei: NEAD/UFSJ, 2015, 25-52.

Villalustre, L., \& Del Moral, M. E. (2016). Realidad aumentada: jugando con la percepción para entender la ciencia en las enseñanzas no universitarias. In: Villalustre, L.; Del Moral, M. E. (Coord.). Experiencias interactivas con realidad aumentada en las aulas. Barcelona: Octaedro. 31-54. 